\title{
Reflexiones sobre el uso del material cartográfico como herramienta pedagógica en América Latina: una función marginalizada ante la función estratégico-legal
}

\author{
Vildan Bahar Tuncay*
}

En el marco de las reivindicaciones de los movimientos sociales indígenas de la última década, el papel del patrimonio cartográfico ha sido esencialmente de índole estratégico. Varias comunidades u organizaciones indígenas elaboraron mapas usados como herramientas de contestación política. El objetivo último de dichos mapas es demonstrar la continuidad histórica de la ocupación de un territorio dado y hacer hincapié en vínculos espirituales, históricos y económicos entre el territorio reivindicado y la comunidad reivindicadora. Desde esta perspectiva, en el presente documento de reflexión se plantea que en el contexto de la emergencia de los movimientos sociales indígenas latinoamericanos, la función del patrimonio cartográfico como herramienta pedagógica en la enseñanza de la historia y de las prácticas espaciales de los pueblos de América Latina se vio relegada a un segundo plano en comparación con su función estratégico-legal para subvertir las relaciones de poder. En otras palabras, el valor cultural e histórico del material cartográfico se ha marginalizado ante su valor subversivo.

Basándose en la revisión de la literatura relativa a la historia de la cartografía en América Latina y a la cartografía participativa en varios países del continente, el documento se refiere a dos fenómenos para explicar la marginalización de la función pedagógica del material cartográfico como herramienta pedagógica en el contexto latinoamericano. El primer fenómeno es la monopolización de las investigaciones relativas al patrimonio cartográfico de los pueblos de América Latina por una sub-categoría en los estudios cartográficos, que es la contra-cartografía indígena.

El segundo fenómeno es la inexistencia de una cuantiosa producción literaria dedicada específicamente al valor histórico y cultural del patrimonio cartográfico. Aunque existe una literatura relativa a la historia de la cartografía, al poder de representación de la cartografía y a su papel en la reconstrucción de las territorialidades indígenas, en esta literatura el enfoque no es el valor histórico y cultural del patrimonio cartográfico propiamente dicho, ni su uso como herramienta pedagógica. También existen trabajos académicos que tratan sobre la cartografía del Nuevo Mundo producida por los españoles y las representaciones occidentales relativas a las cartografías de los pueblos conquistados. En el conjunto de toda esta literatura, el enfoque no es el patrimonio cartográfico

* Cómo citar este artículo: Tuncay, V. B. (2013). Reflexiones sobre el uso del material cartográfico como herramienta pedagógica en América Latina: una función marginalizada ante la función estratégico-legal. En Apuntes 26 (1): 78 - 87. 


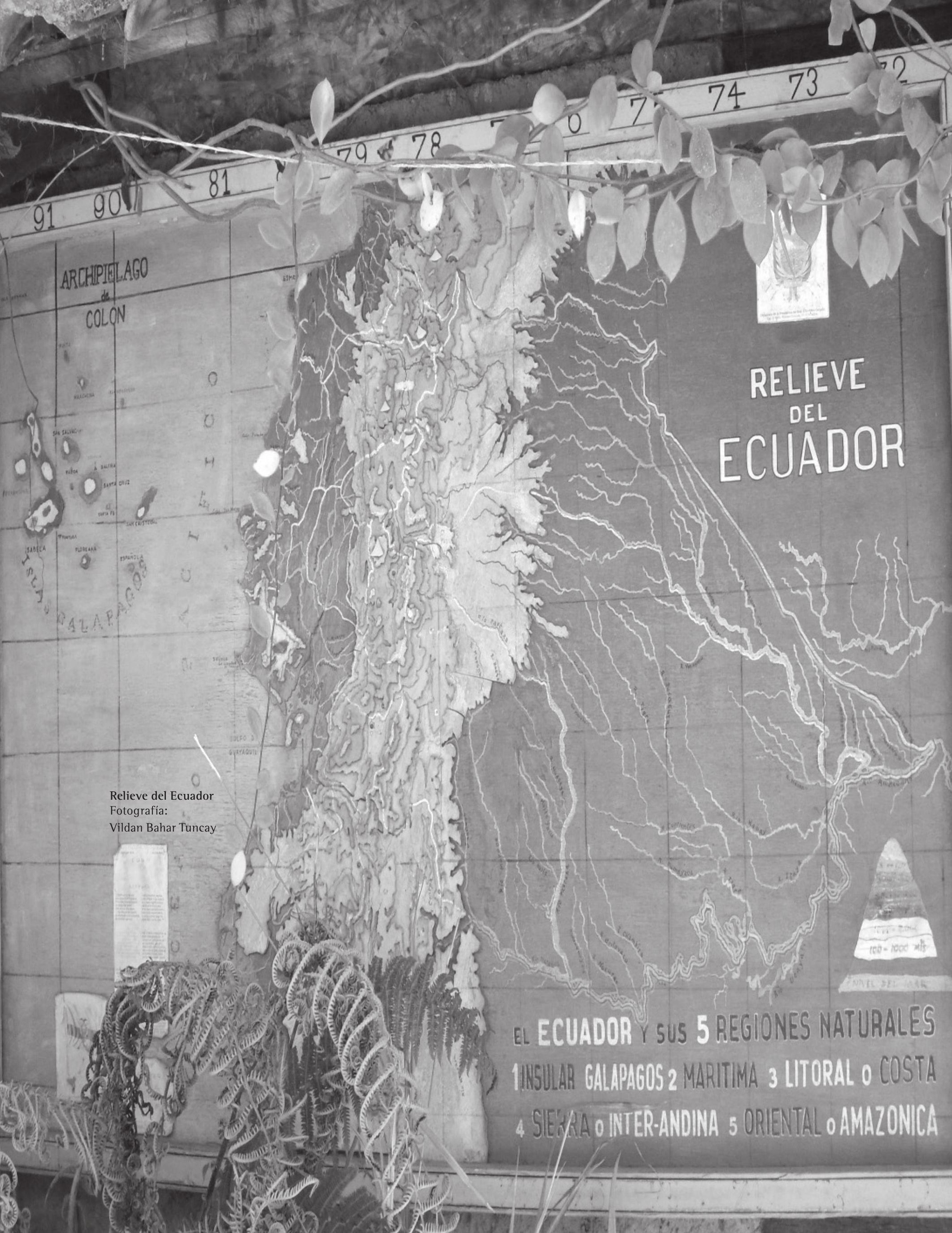




\section{Reflexiones sobre el uso del material cartográfico como herramienta pedagógica en América Latina: una función marginalizada ante la función estratégico-legal}

Reflections on the Use of Maps as a Pedagogical Tool in Latin America: A

Marginalized Function in Comparison to the Strategic-Legal Function

Reflexões sobre o uso dos mapas como ferramenta pedagógica na América

Latina: uma função função para estratégico marginalizadas-legal

\section{Vildan Bahar Tuncay}

barbaratuncay@yahoo.com.mx

Cursó pregrado en Estudios Hispánicos, posgrado en Ciencia Política y un estudio certificado en Antropología Social y Cultural de la Universidad Laval de Québec, Canadá. Durante sus estudios, realizó varias estadías académicas en América Latina, más precisamente en Ecuador, Colombia, Perú, México y Panamá. Realiza un Doctorado en Ciencias Geográficas de la Universidad Laval de Québec y en el marco de sus estudios doctorales, trabaja sobre las identidades indígenas de la costa ecuatoriana.

Universidad Laval, Québec, Canadá

Resumen

El presente documento trata sobre el uso del patrimonio cartográfico de los pueblos latinoamericanos como herramienta pedagógica en un entorno socio-político marcado por la emergencia de movimientos sociales indígenas que reclaman sus derechos territoriales y ancestrales. En este contexto, la función de la cartografía como herramienta pedagógica en la enseñanza de la historia y de las prácticas espaciales y cartográficas de los pueblos de América Latina se relegó a un segundo plano en comparación con su función estratégico-legal para subvertir las relaciones de poder. El documento se basa en dos fenómenos para explicar las razones por las cuales el patrimonio cartográfico no alcanza su pleno potencial como herramienta pedagógica en diferentes niveles de educación en América Latina. En la literatura existente relativa a la historia de la cartografía, al poder de representación de la cartografía o a su papel en la reconstrucción de las territorialidades indígenas, el enfoque no es el valor histórico y cultural del material cartográfico propiamente dicho ni su uso como herramienta pedagógica.

Palabras clave: Patrimonio cartográfico, prácticas espaciales, prácticas cartográficas, capital espacial, encuentro cartográfico

Descriptores: Historia-Métodos de estudio, América Latina-Movimientos sociales, Cartografía- América Latina, Indígenas-Aspectos sociales, derechos de los indígenas

Abstract

This paper discusses the use of cartographic heritage of Latin American tribes as a pedagogical tool in spaces marked socio-politically by the emergence of indigenous social movements claiming their ancestral territorial rights. In this context, the role of cartography as a pedagogical tool for teaching history and spatial and cartographic practices of the peoples of Latin America was relegated to the background in comparison to the strategic-legal function adopted to subvert power relations. The paper is based on two phenomena to explain the reasons why the cartographic heritage does not reach its full potential as a teaching tool at different levels of education in Latin America. In the existing literature about the history of cartography, the power of representation mapping has, or its role in the reconstruction of indigenous territoriality, the approach is not the historical and cultural value or cartography, nor its function as a teaching tool.

Keywords : Cartographic heritage, spatial practices, cartographic practices, spatial capital, cartographic encounters

Artículo de reflexión

El presente documento de reflexión trata sobre el uso del patrimonio cartográfico de los pueblos latinoamericanos como herramienta pedagógica en un entorno socio-político marcado por la emergencia de movimientos sociales indígenas que reclaman sus derechos territoriales y ancestrales.

Recepción: 1 de octubre de 2012.

Aceptación: 1 de junio de 2013.
Keywords plus: History-methods study, Latin America, Social Movements, Mapping, Latin America, Indigenous, Social, indigenous rights

Resumo

Este artigo discute o uso do patrimônio cartográfico dos povos latino-americanos como uma ferramenta pedagógica em uma sociopolítica marcada pelo surgimento dos movimentos sociais indígenas que reivindicam seus direitos territoriais ancestrais. Neste contexto, o papel da cartografia como ferramenta pedagógica no ensino de história e práticas espaciais e cartográficas dos povos da latine Latina foi relegado para segundo plano em comparação com função estratégica-legal para subverter as relações poder. 0 documento baseia-se em dois fenômenos para explicar as razões pelas quais o património cartográfico não atingir o seu pleno potencial como ferramenta de ensino em diferentes níveis de ensino na América Latina. Na literatura existente sobre a história da cartografia, o poder de representação do mapeamento ou o seu papel na reconstrução da territorialidade indígena, a abordagem não é histórico e cultural próprio valor material cartográfico ou usado como uma ferramenta de ensino.

Palavras-chave: mapeamento Heritage, práticas espaciais, práticas cartográficas, capital reunião mapeamento espacial

Palavras-chave descritores: Métodos história-estudo, América Latina- Movimentos Sociais, mapeamentoAmérica Latina, direitos indígenas Indígena-social

doi:10.11144/Javeriana.APC26-1.rsum

* Los descriptores y keywords plus están normalizados por la Biblioteca General de la Pontificia Universidad Javeriana. 
de los pueblos de América Latina, sino cómo era percibido por los españoles. Es decir, esta literatura aborda cómo, dentro del proceso de colonización y después de las independencias, la cartografía indígena fue considerada poco cientifica en comparación con los mapas elaborados en el mundo occidental según el método cartesiano. Además, los trabajos relativos al valor histórico de la cartografía están mayoritariamente escritos en inglés ${ }^{1}$ y el acceso de los estudiantes o docentes latinoamericanos a esta literatura es relativamente limitado.

Para tratar el uso del patrimonio cartográfico de pueblos latinoamericanos como herramienta pedagógica en un entorno socio-político marcado por la emergencia de movimientos sociales indígenas, se hará en primer lugar un estado de la cuestión relativo a los factores que influyen generalmente en el uso del material cartográfico como herramienta pedagógica. En segundo lugar, se realizará un recorrido histórico para atestiguar la formación del patrimonio cartográfico latinoamericano en sus grandes líneas. En tercer lugar, se abordará más específicamente la marginalización de la función pedagógica del material cartográfico frente a su función estratégico-legal en el contexto de las reivindicaciones territoriales indígenas en el continente latinoamericano.

\section{Uso del material cartográfico como herramienta pedagógica en el contexto latinoamericano}

Hay un consenso entre los académicos en lo que se refiere a la pertinencia de usar el material cartográfico (mapas y planes) como herramienta pedagógica. Dicho consenso proviene del hecho de que este material constituye un sistema de significados a través del cual se comunica, reproduce, experimenta y explora un orden social. Desde esta perspectiva, el material cartográfico describe el mundo como cualquier otro tipo de fuente primaria en términos de relaciones y prácticas de poder, preferencias y prioridades culturales (Harley, 2005, p. 61 y 73). Sin embargo, generalmente, se observa un cierto desinterés (Dym y Offen, 2012, p. 213), hasta una reticencia en su uso como material pedagógico y como fuente primaria en la comprensión y la enseñanza de la historia. Harley indica que:
Los historiadores tienden a relegar los mapas, junto con cuadros, fotografías y otras fuentes no verbales a un tipo de evidencia de menor categoría que la palabra escrita. Aún cuando se admite que los mapas son documentos, se les considera útiles principalmente en pocas cuestiones históricas determinadas, para responder a alguna pregunta relativamente limitada acerca de la ubicación o la topografía y con menor frecuencia, para aclarar la historia cultural o los valores sociales de algún periodo o lugar especial. (Harley, 2005, pp. 59-60)

Por lo que se sabe de la literatura existente, en mayor medida, las razones del desinterés se buscó en la actitud de los historiadores (Harley, 2005, pp. 59-60) o en las barreras artificiales que dividen las disciplinas académicas (Dym y Offen, 2012, p. 214). También se consideró a los mapas como un material vulnerable frente a diferentes tipos de fenómenos, como incendios o inundaciones y susceptibles de ser empleados con propósitos distintos a los previstos inicialmente. Además, a veces las autoridades estatales destruyen deliberadamente ciertos mapas por razones de seguridad nacional o control militar (Craib, 2000, p. 9), o los usan como legitimadores de proyectos oficiales.

En cuanto al uso del material cartográfico en el contexto latinoamericano más específicamente, también se reconoce el valor del material cartográfico como fuente primaria de información para historiadores y geógrafos. No obstante, en la literatura relativamente escasa sobre la cartografía latinoamericana y en los trabajos de los latinoamericanistas, la geografía y la historia son dos áreas de trabajo distintas y generalmente, los análisis espaciales se ven relegados a un segundo plano frente a los análisis temporales. De hecho, los académicos suelen prestar poca atención a los procesos socio-históricos de la configuración de los territorios y sus manifestaciones cartográficas. (Craib, 2000, pp. 9-10). Además, cabe recordar que los originales de una gran parte del patrimonio cartográfico de los pueblos de América Latina se encuentran hoy en día en museos occidentales $^{2}$. Esta situación disminuye la accesibilidad a todo el material cartográfico por parte de los docentes y estudiantes latinoamericanos.
1. Las obras a las que se refiere son: Traveling from New Spain to Mexico de Magali Carrera (2011); The Mapping of New Spain de Barbara Mundy (2000); y Mapping Latin America. A cartographic reader de Dym y Offen (2011).

2. Es el caso de las representaciones cartográficas contenidas en las relaciones geográficas de la época colonial, la mayoría se encuentra actualmente en la Benson Latin American Collection de la Universidad de Texas.

81 
Capital espacial prehispánico

y patrimonio cartográfico

En la época prehispánica, los pueblos nativos de América Latina tenían un profundo conocimiento geográfico y cognitivo de sus territorios (Herlihy, 2003, p. 324). La mayoría se desplazaba en grandes territorios en función del clima, de la cantidad de precipitaciones y de la disponibilidad de los recursos, como los grupos de Darién en Panamá, las poblaciones prehispánicas de la costa ecuatoriana o los pueblos nativos de la Amazonía (Herlihy, 2003, p. 324; Álvarez, 2002, p. 30, Chase Smith, Benavides, Pairona y Tuesta, 2003, p.367). Es preciso decir que las habilidades cartográficas de los pueblos eran muy variables: mientras que los pueblos de Mesoamérica tenían las técnicas más avanzadas de la época, los de la Amazonía funcionaban más bien con mapas mentales (Herlihy, 2002, p. 135). Cabe mencionar que las representaciones cartográficas de esa época reflejaban las cosmovisiones de los pueblos nativos.

Más tarde, a pesar de haber sido destrui-

3. En las ciencias geográficas, el capital espacial se define como "el conjunto de conocimientos y experiencias acumulados por el actor que le permiten beneficiarse de los recursos disponibles en una sociedad. Tal como el capital económico que implica un patrimonio y la capacidad de sacar provecho a este, el capital espacial implica un patrimonio y unas competencias". (Lévy y Lussault, 2003, pp. 125-126).

4. En Mesoamérica, estos hombres o mujeres hábiles en el dibujo se calificaban como tlahcuilos.

5. Según los estudios de Mundy, entre 69 mapas contenidos en las relaciones geográficas de Nueva España, un 65\% fue elaborado por artistas indígenas. (Mundy, 2000, p. 30).

6. La obra está dividida en dos partes: la Nueva Corónica trata sobre el pasado andino hasta la llegada de los españoles y El buen gobierno que relata los hechos posteriores a la conquista con un análisis crítico de la administración colonial española.
(Harley, 1992, p. 528). A diferencia de los textos escritos por los funcionarios españoles, los mapas agregados a las relaciones fueron en su gran mayoría elaborados por élites pertenecientes a la República de indios y elegidas precisamente por su talento y larga tradición de escribir-pintando ${ }^{4}$ (Mundy, 2011, pp. 51-52)

Las ilustraciones no siempre correspondían a las expectativas de las autoridades españolas por dos razones principales. En primer lugar, el objetivo primordial de las autoridades españolas al recolectar datos era de índole administrativo, ya que buscaban informaciones susceptibles de ser usadas para desarrollar actividades económicas, más precisamente, para la explotación de recursos mineros. (Carrera, 2011, p. 49 y 62). En segundo lugar, en las ilustraciones los espacios estaban representados con referencias a los lazos históricos, religiosos y sociales que unen los habitantes a este espacio. Es decir, a diferencia de los españoles que usaban coordenadas matemáticas para representar el espacio, las élites indígenas usaban coordenadas culturales (Carrera, 2011, p. 45; Mundy, 2000, prefacio).

Al mismo tiempo, el contacto con el mundo occidental implicaba también un contacto cartográfico en el sentido en que durante el proceso de colonización, los pueblos indígenas empezaron progresivamente a sufrir cambios en sus representaciones espaciales y territoriales, igual que en sus prácticas cartográficas. Desde esta perspectiva, el material cartográfico presentado en las relaciones transmite al mismo tiempo las representaciones espaciales de los pueblos indigenas que sufrían unos cambios tras el contacto.

El primer nueva corónica y buen gobierno ${ }^{6}$ de Felipe Poma de Ayala (1530?1540?-1616) es una obra fundamental que combina el texto y la imagen e ilustra los efectos de la colonización sobre las representaciones territoriales, las prácticas cartográficas y el imaginario de los pueblos nativos. Cabe recordar que, los efectos de la explotación económica y social propios al sistema colonial se empezaron a sentir progresivamente y la obra de Poma de Ayala, además de ilustrar el universo mental de su autor, las concepciones del espacio, del tiempo y de la historia en el Imperio inca y relatar los problemas de la administración colonial española, usa representaciones cartográficas para reivindicar derechos ancestrales y apoyar las peticiones (Adorno, 2011, pp. 74-75). 
El mapa de las tierras de Oztotícpac ${ }^{7}$ de 1540 demuestra la consolidación progresiva de la tradición indígena-mesoamericana de respaldar reclamos con dibujos utilizando glifos y papel amate. En ese sentido, la creación de una nueva producción cartográfica indígena era un medio según los pueblos para reducir tensiones sociales y mantener una identidad colonial indígena. (Craib, 2000, p. 25)

El potencial del corpus contenido en las relaciones y las representaciones cartográficas contenidas en las peticiones de parte de los miembros de la República de indios a las autoridades españolas son infrautilizados en los recursos pedagógicos como parte del patrimonio cartográfico y fuente primaria de información sobre la realidad socio-política e histórica latinoamericana.

\section{Marginalización de la función pedagógica del patrimonio cartográfico ante su función estratégico-legal}

Aunque existe literatura sobre la historia de la cartografía, el poder de representación de la cartografía o su papel en la reconstrucción de las territorialidades indígenas, el enfoque no es el valor histórico y cultural del patrimonio cartográfico propiamente dicho ni su valor agregado como material pedagógico. Más bien, bajo la literatura estudiada el patrimonio cartográfico es visto como un elemento constitutivo del capital espacial y de las representaciones territoriales de los pueblos de América Latina. Cabe añadir que los trabajos sistemáticos que tratan sobre el valor histórico de la cartografía están mayoritariamente escritos en inglés y el acceso de los estudiantes o docentes latinoamericanos a esta literatura debe de ser relativamente limitado.

A estas afirmaciones de orden general se suman las particularidades del contexto latinoamericano posguerra fría: El período marcado por el fin de los regímenes dictatoriales y la transición a la democracia fue testigo de la emergencia de los movimientos sociales indígenas en varios países de la región. En el marco de estos movimientos, la valorización de los territorios ancestrales y las reivindicaciones territoriales ocupan un lugar fundamental. No es sorprendente que en este mismo período, sea contestado, entre otras cosas, el monopolio de representación que perteneció durante siglos a las élites blancas y mestizas. Durante siglos, las toponimias indígenas se vieron eliminadas de la cartografía oficial y las tierras indígenas se etiquetaron como baldías (Sletto, 2010, p. 44). Por lo tanto, con su poder de representación, el papel tanto real como simbólico de la cartografía, adquiere una importancia muy particular por los que "retornan al escenario político para convertirse en sus propios imagineros" (Muratorio, 1994, p. 9) ${ }^{8}$.

En este nuevo contexto, a principios de la década de 1990, empezaron a llevarse a cabo varios proyectos de cartografía en diferentes comunidades indígenas del continente. Algunos de ellos se realizaron por la iniciativa de las organizaciones socio-políticas indígenas, como los mapas elaborados por la Confederación de las Nacionalidades Indígenas del Ecuador (CONAIE). Otros proyectos se desarrollaron en forma de cartografía participativa en México, Panamá, Bolivia, Honduras, Chile y Nicaragua con la contribución de académicos europeos y norteamericanos.

Estas diferentes iniciativas se califican como contra-cartografías indigenas por ser alternativas frente a los mapas oficiales producidos por Estados-Naciones. En este contexto, diferentes grupos o movimientos indígenas usaron el material cartográfico que elaboraron como herramienta de contestación política con el objetivo de demonstrar la continuidad histórica de su ocupación del territorio subrayando las dimensiones espirituales, económicas y residenciales de la relación que les une a ese territorio. (Hirt, 2009, p. 173). La cartografía se convierte entonces en una documentación escrita y gráfica de sus reivindicaciones por tierras, territorios y recursos, una herramienta que busca subvertir las relaciones de poder propias del colonialismo interno de repúblicas criollas. (Hirt, 2007, p. 71).

Los ejemplos del uso de la cartografía como una herramienta de empoderamiento en busca del control de un territorio dado son numerosos. Uno de los más llamativos pertenece al movimiento mapuche. Las producciones cartográficas mapuche constituyen una expresión emblemática del proceso de reapropriación territorial y decolonización de los saberes y representaciones. (Hirt, 2007, p. 78).

En Ecuador, CONAIE elaboró una serie de mapas a lo largo de la década pasada para demostrar la continuidad histórica de las nacionalidades, mientras que los mapas elaborados al inicio de la década de 1990 solo representaban algunas de las nacionalidades sobrevivientes al período colonial
7. Este mapa que se remonta a 1540 es un documento pictórico escrito en español y náhuatl, está vinculado con un litigio por los bienes del patrimonio de don Carlos Ometochtli Chichimecatecotl. El litigio comenzó en 1540 cuando un hombre, identificado como Pedro de Vergara, solicitó a la Inquisición que le devolviera ciertos árboles frutales que se habían confiscado de la propiedad de don Carlos. Este reclamaba los árboles en virtud de un contrato que había concluido con don Carlos varios años atrás. Otras personas sostenían que las tierras ocupadas por don Carlos no le pertenecían a él personalmente sino a la familia -los nobles de Texcoco- en su conjunto. Lo más probable es que este mapa haya sido encargado por Antonio Pimentel Tlahuilotzin, gobernador de Texcoco, para respaldar estos reclamos. (Mundy, 2011, pp. 56-60).

8. "En la realidad social y política contemporanea de America Latina, el monopolio de ese poder de representación esta siendo cuestionado por los mismos representados quienes, cansados de jugar un rol secundario en una imagen del pasado creado por otros, retornan el escenario politico para convertirse en sus propios imagineros" (Muratorio,1994, p. 9). 


\section{La comunidad embera de Ipetí en Panamá, \\ una de las comunidades más afectadas por \\ la expansión de las \\ fronteras de colonización y la deforestación. \\ Fuente: \\ Vildan Bahar Tuncay}

9. "Como era de esperarse, los líderes indígenas que experimentaron tales cambios territoriales estaban muy interesados en los proyectos de mapeo. Aprendieron la importancia de elaborar mapas precisos durante sus campañas comarcales y reconocieron los problemas en los mapas estatales que clasificaron mal o no representaron correctamente sus asentamientos. Muchos se sintieron mal representados 0 infra-representados y vieron los proyectos de mapeo como una oportunidad para cambiar esta situación. Las autoridades emberá también se preocuparon por los problemas relacionados con la invasión de sus tierras comarcales por los colonos. Entendieron el poder de los mapas y la utilidad de la documentación sistemática y científica de sus tierras para tratar una variedad de temas" (Herlihy, 2003, p. 320) (traducción de la autora).

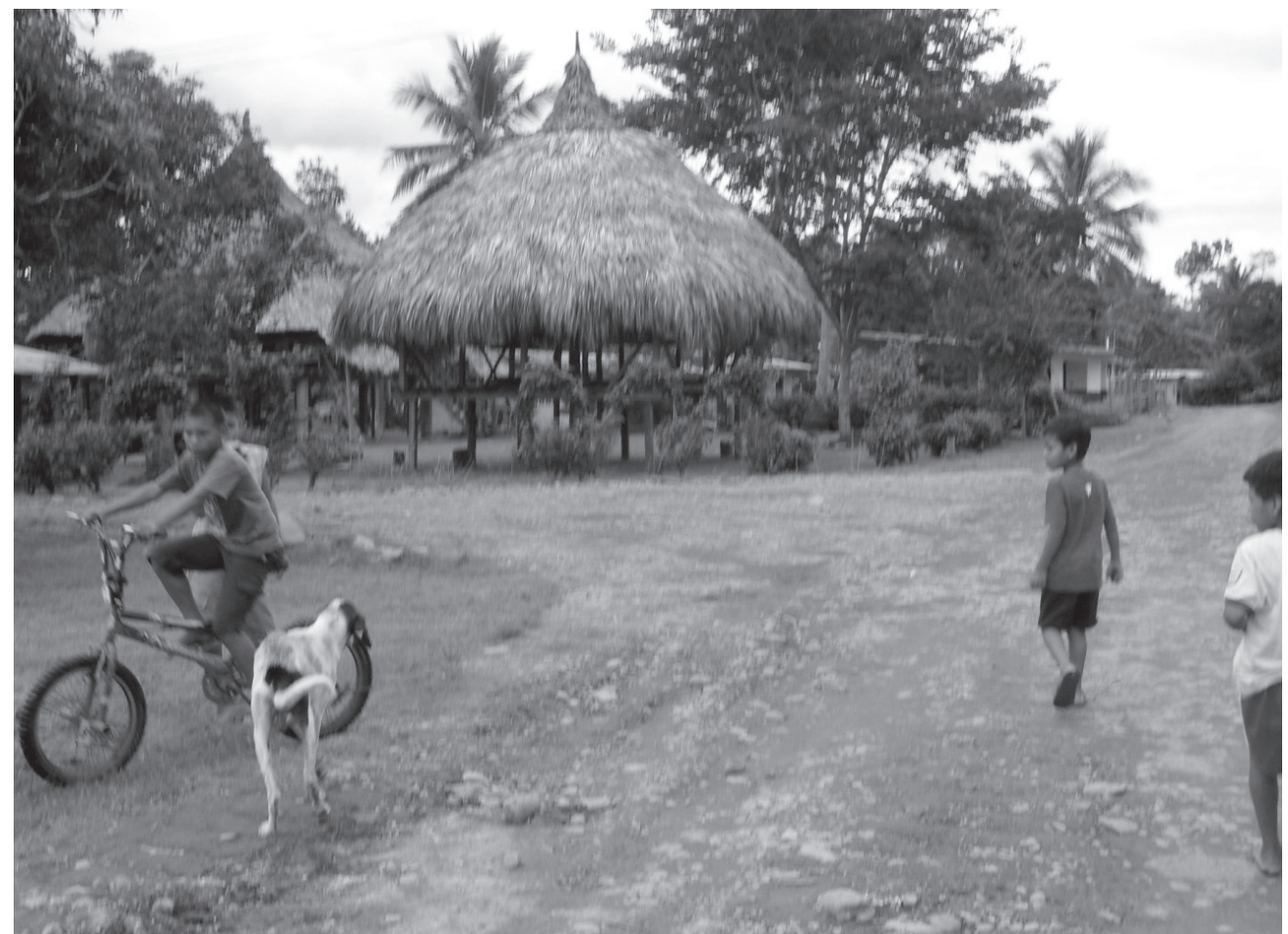

y republicano. Con el progreso del desarrollo dado en el proceso de reestructuración del movimiento indígena al nivel nacional, los mapas que se venían elaborando empezaron a abarcar más nacionalidades presentes en el territorio nacional. (Pajuelo, 2007, p. 141)

En Panamá también se observa una serie de actividades cartográficas durante la década de 1990. En ese país, tanto en las comunidades de la región de Darién como en las ngöbe-buglés, las invasiones de los colonos o taladores ilegales constituyen el punto de partida de las iniciativas cartográficas. Herlihy indica que:

Indigenous leaders, having experienced such remarkable territorial changes, were understandably very interested in the mapping project. They learned the importance of accurate maps during their comarca campaigns, and they recognized problems with state maps that mislabeled or failed to show their settlements. Many felt either misrepresented or underrepresented, and they saw the mapping project as an opportunity to change this situation. Emberá authorities were also concerned about problems related to the invasion of comarca lands by colonists. They had a keen sense of the power of maps and understood the usefulness of systematic, "scientific" docu- mentation of their lands for dealing with a variety of issues (Herlihy, 2003, p. 320) ${ }^{9}$.

Experiencias similares se vivieron en $\mathrm{Ni}$ caragua y Belize. En Nicaragua los proyectos cartográficos coinciden con el objetivo de las comunidades indígenas de construir una base legal a la amenaza de concesiones otorgadas por el gobierno a una empresa internacional. En Belize, similarmente, los grupos indígenas usaron proyectos de cartografía para proteger sus derechos ancestrales frente al Estado que no quería reconocerlos. (Wainwright y Bryan, 2009, pp. 153-178). El elemento común de estos ejemplos está en que los orígenes de las iniciativas cartográficas no son las necesidades cartográficas de las comunidades propiamente dichas, sino motivos de fortalecimiento de una organización política indígena, reivindicación o protección territorial frente a las políticas públicas o actividades de explotación de los recursos ubicados en sus territorios.

A partir de estas experiencias se formó una literatura constituida por los académicos europeos o norteamericanos que, en la mayoría de los casos, formaron parte de diferentes proyectos de cartografía participativa ya mencionados. Cabe señalar que estos trabajos no tratan sobre el valor cultural e histórico del patrimonio cartográfico de los pueblos propiamente dicho. Estos reflejan las percepciones y perspectivas de los académicos 
extranjeros sobre procesos de cartografía participativa y sus resultados para las comunidades en términos de definición de los territorios por fines de control y conservación de los recursos ante los intereses de terceros: Estado, colonos, talladores ilegales o empresas internacionales. Cabe recalcar que dentro de esta misma literatura también hay visiones críticas que sostienen que los mapas elaborados en este contexto no siempre reflejan las complejas relaciones sociales del mundo indígena, ni la dinámica, superpuesta y cambiante concepción indígena del espacio (Sletto, 2010, p. 44). Efectivamente, a pesar de contar con la participación indígena en el proceso, un solo proyecto de cartografía participativa no puede abarcar el conjunto del patrimonio cartográfico de un pueblo o de una comunidad dada.

En toda esta literatura, aunque se reconoce el vasto conocimiento cartográfico de los pueblos, se recurre a la producción de mapas mentales y se revisitan ciertas prácticas espaciales de las comunidades involucradas. Estos elementos no están siendo reconocidos por su valor intrínseco sino que constituyen un elemento, entre muchos otros, del proceso de reconstrucción contemporáneo de las territorialidades indígenas. $Y$ más importante aún, no se establecen relaciones entre estos proyectos con el patrimonio cartográfico de los pueblos involucrados. Es decir, la literatura reciente sobre diferentes proyectos de mapeo indígena o cartografía participativa no están siendo relacionados con la tradición de usar deliberadamente los mapas como herramienta de reivindicación que remonta sus orígenes al principio del proceso de colonización. Como se mencionó anteriormente, esta práctica empezó en el siglo XV1 y se consolidó como una tradición de resistencia en las colonias españolas. Sin embargo, la manera como se presentan los diferentes proyectos de cartografía participativa en la literatura da la impresión de que se trata de prácticas nacidas en el período actual en el contexto de las reivindicaciones territoriales.

\section{Conclusiones}

El contexto descrito explica las razones por las cuales el patrimonio cartográfico se ve marginalizado como herramienta pedagógica en América Latina. En primer lugar, los mapas elaborados como contra-cartografías indigenas se ven sobre-representados en la literatura reciente y parecen monopolizar las investigaciones relativas al patrimonio cartográfico de los pueblos de América Latina. También, parece que en el marco de las reivindicaciones territoriales indígenas, el patrimonio cartográfico se identifica exclusivamente con su función pragmática o estratégica, como herramienta de empoderamiento territorial. Dentro de este esquema, el capital espacial de los

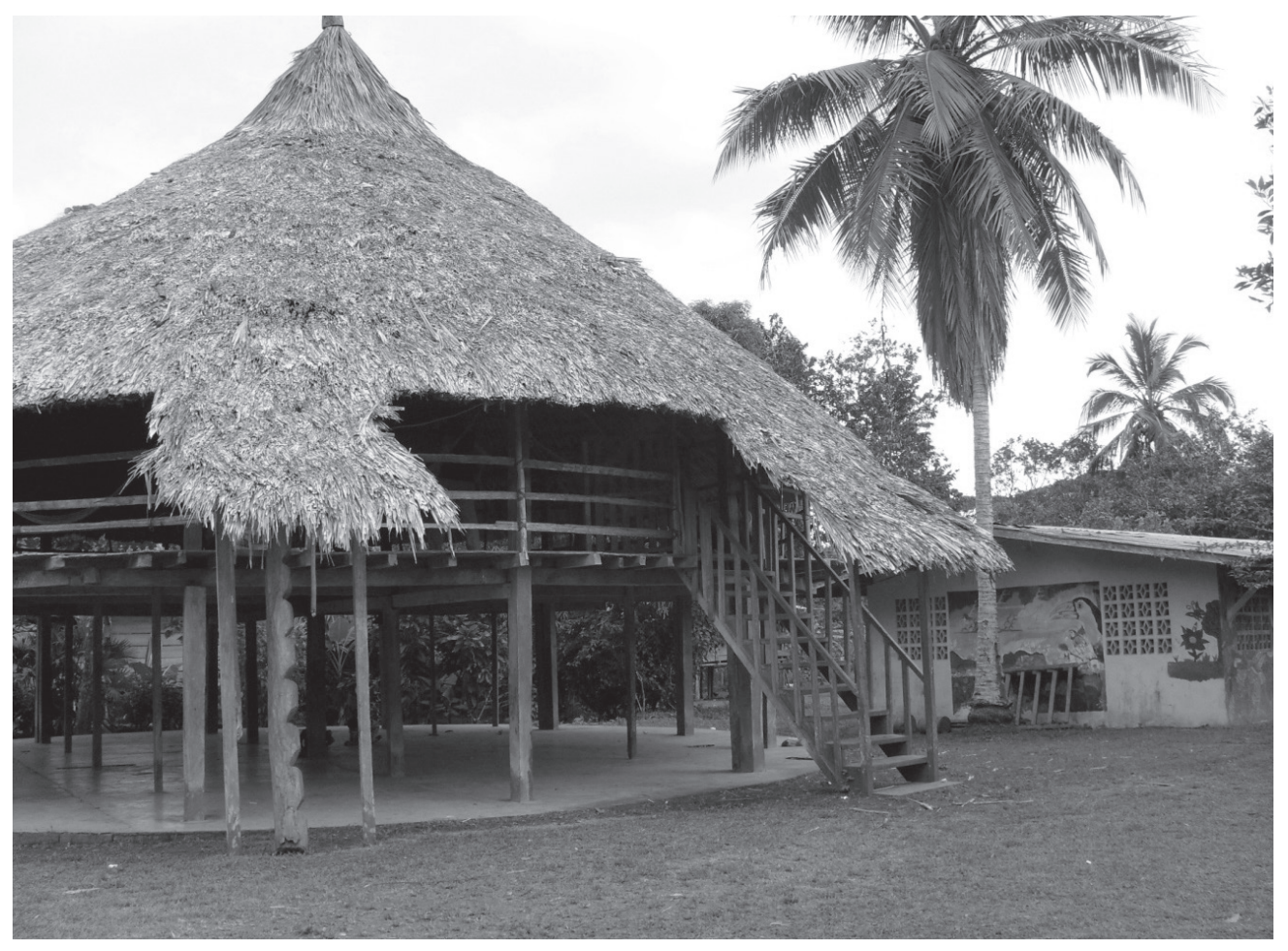

Figura 2. Comunidad embera del Ipetí, Panamá. Fuente: Vildan Bahar Tuncay 
pueblos, el valor histórico de los mapas y planos no se ven valorizados como herramienta pedagógica. Aunque la literatura reconoce la toma de consciencia por parte de los integrantes de las comunidades sobre las prácticas cartográficas por la supervivencia cultural (Sletto, 2010, p. 71), el lugar que le está otorgando a este aspecto queda en una posición marginal en comparación con la importancia acotada al empoderamiento territorial mediante el uso de las cartografías indígenas.

Como lo señala Harvey, los mapas responden a una realidad sociopolítica e histórica específica y desde esta perspectiva, el contexto socio-político actual favorece una cartografía comprometida con reconfiguración territorial y los intereses cartográficos responden más bien a los objetivos políticos de diversos movimientos sociales indígenas que a la valorización cultural e histórica intrínseca del material cartográfico. El contexto actual de reivindicaciones territoriales no crea un entorno favorable para la integración del material cartográfico en los recursos pedagógicos ya que las contra-cartografías indígenas son elaboradas como alternativas a la cartografía oficial de los Estados-Naciones. Paralelamente, como se mencionó anteriormente, en los trabajos académicos acerca de la cartografía participativa los aspectos más destacados son la reapropiación territorial y la protección de los derechos territoriales una vez definidas las demarcaciones territoriales, al igual que el uso de los resultados de estas iniciativas en las negociaciones con el Estado. En conclusión, la instrumentalización del material cartográfico por fines políticos tiene como corolario la marginalización de la función pedagógica del mismo.

\section{Referencias}

Adorno, R. (2011). Andean Empire. En J. Dym y K. Offen (Eds.). Mapping Latin America. A cartographic reader (pp.74-78). Chicago: The University of Chicago Press.

Álvarez, S. (2002). De reducciones a comunas: transformaciones legales de las tierras comunales en la península de Santa Elena, Ecuador, Quaderns de l'Institut Català d'Antropologia, (17-18), 7-43.

Carrera, M. (2011). Traveling from New Spain to Mexico. Mapping practices of nineteenthcentury Mexico. London: Duke University Press.
Chase Smith, R., Benavides, M., Pairona, M. y Tuesta, E. (2003). Mapping the Past and the Future: Geomatics and Indigenous Territories in the Peruvian Amazon, Human Organization, 4 (62), 357-368.

Craib, R. (2000). Cartography and power in the conquest and creation of New Spain. Latin American Research Review, 35 (1), 7-36

Dym, J. y Offen, K. (2012). Maps and the Teaching of Latin American History. Hispanic American Historical Review, 92 (2), 213-244.

Estrada-Belli, F. y Hurst, H. (2011). Palace Arts. En J. Dym y K. Offen (Eds.). Mapping Latin America. A cartographic reader (pp. 2528). Chicago: The University of Chicago Press.

Harley, B. (1992). Rereading the maps of the Columbian encounter. Annals of the Association of American Geographers, 82 (3), 522-536.

Harley, B. (2005). La nueva naturaleza de los mapas. Ensayos sobre la historia de la cartografía. México: Fondo de Cultura Económica.

Herlihy, P. (2002), Indigenous Mapmaking in the Americas: A Typology. Cultural and physical expositions: Geographic Studies in the Southern United States and Latin America (pp.133-150). Lousiana: Louisiana State University.

Herlihy, P. (2003). Participatory Research Mapping of Indigenous Lands in Darién, Panama. $\mathrm{Hu}$ man Organization, 62 (4), 315-331.

Herlihy, P. y Knapp, G.(2003). Maps of, by, and for the peoples of Latin America, Human Organization, 62 (4), 303-314.

Hirt, 1. (2007). Géographies de la résistance et de la colonisation: une approche de la reconstruction des territoires mapuche du Chili, Géographie et cultures (63), 67-86.

Hirt, 1. (2009). ¿Para qué construir irreversibilidades? La recontrucción de Chodoy Lof Mapu, una experiencia autónoma de cartografía mapuche en el Sur de Chile. En J. Calbucura y F. Le Bonniec (Eds.) Territorio y territorialidad en contexto post-colonial Estado de Chile-Nación mapuche (pp.80-106). Ñuke Mapuförlaget.

Hirt, 1. (2012). Mapping dreams/Dreaming maps: Bridging indigenous and western geographical knowledge. Cartográfica, 47 (2), 105-120.

Lévy, J. y Lussault, M. (2003). Dictionnaire de la géographie et de l'espace des sociétés. Paris: Belin. 
Mundy, B. (2000). The Mapping of New Spain. Indigenous Cartography and the Maps of the Relaciones Geográficas. Chicago: The University of Chicago Press.

Mundy, B. (2011). Hybrid Space. En J. Dym y K. Offen (Eds.). Mapping Latin America. A cartographic reader (pp. 51-55). Chicago: The University of Chicago Press.

Muratorio, B. (1994). Imágenes e imaginarios. Quito: FLACSO Ecuador .

Pajuelo, R. (2007). Reinventando comunidades imaginadas. Movimientos indigenas y procesos sociopolíticos en los países centroandinos. Lima: Instituto de estudios peruanos.
Sletto, B. (2010). Autogestión en representaciones espaciales indígenas y el rol de la capacitación y concientización: el caso del Proyecto etnocartográfico Inna Kowantok, Sector 5 Pemón, La Gran Sabana. Antropológica, (113), 43-75.

Smith, D. (2003). Participatory Mapping of Community Lands and Hunting Yields among the Buglé of Western Panama. Human Organization, 62 (4), 332-343.

Wainwright, J. y Bryan, J. (2009). Cartography, Territory, Property: Postcolonial Reflections on Indigenous Counter-Mapping in Nicaragua and Belize. Cultural Geographies, 16, 153-178.

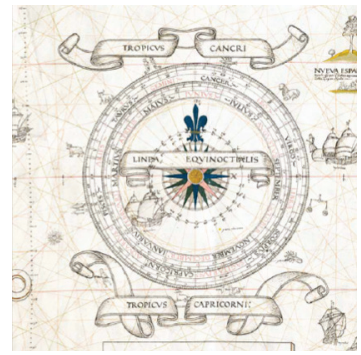

